\title{
Mathematical model of carbon monoxide oxidation: influence of the catalyst surface structure
}

\author{
Kostrobij P., Ryzha I., Markovych B. \\ Lviv Polytechnic National University, \\ 12 S. Bandera Str., Lviv, 79013, Ukraine
}

(Received 25 October 2018)

\begin{abstract}
A substantiated mathematical model is proposed for describing the reaction-diffusion processes of a binary mixture of particles adsorbed on a catalyst surface. It is shown that the proposed model generalizes the one-dimensional ZGB model for carbon monoxide $(\mathrm{CO})$ oxidation reaction. The kinetics of $\mathrm{CO}$ oxidation is investigated on the facets of platinum (Pt) crystal, which are stable with respect to reconstruction.
\end{abstract}

Keywords: reaction of catalytic oxidation, reaction-diffusion model, mathematical modeling of reaction-diffusion processes.

2000 MSC: 37E99, 82D99, 82C21

UDC: 538.9

DOI: $10.23939 / \mathrm{mmc} 2018.02 .158$

\section{Introduction}

Investigation of the mechanisms of reaction-diffusion processes in systems of atoms adsorbed on metal catalysts surface is one of the actual problems of modern mathematical modeling of surface phenomena [1]. Mathematical models of such processes are constructed on the basis of reaction-diffusion equations, obtained phenomenologically or semi-phenomenologically using certain statistical approaches [2] with mainly experimentally determined rates of adsorption, desorption, diffusion and chemical reactions [3]. In particular, the processes of carbon monoxide (CO) oxidation on platinum (Pt) surface are described using equations of chemical kinetics based on the ZGB model $[4,5]$.

In papers $[1,6]$ a quantum-statistical approach was proposed for subsequent derivation of kinetic equations for chemical reactions on metal surfaces. It allowed obtaining the reaction-diffusion equations for kinetics of chemical reactions on metal surfaces in general form.

In this paper, a simplified mathematical model for describing $\mathrm{CO}$ oxidation processes on platinum catalyst surface is obtained from the general equations of chemical kinetics for reaction-diffusion processes of particles adsorbed on metal surfaces. It takes into account all the peculiarities of such processes in the LH model. It is shown that proposed model generalizes the ZGB model. Within the framework of the proposed model the kinetics of $\mathrm{CO}$ oxidation is investigated on the facets of $\mathrm{Pt}$ crystallites, which are stable with respect to reconstruction.

\section{Mathematical model of carbon monoxide oxidation}

We consider a two-component mixture of $A(\mathrm{CO})$ and $B\left(\mathrm{O}_{2}\right)$ particle species that can chemically react forming a product of reaction, the complex $A B\left(\mathrm{CO}_{2}\right)$. We assume that chemical reaction of synthesis

$$
A+B \rightarrow A B
$$

is possible only when particles $A$ and $B$ are adsorbed on the catalyst surface (Langmuir-Hinshelwood reaction (LH) [7]). 
If particles are adsorbed at certain places of a catalyst surface (hereinafter, these places will be called adsorption sites) and after adsorption "meet" due to diffusion processes and participate in a chemical reaction, it is convenient to introduce into consideration the functions: $f_{A}(\alpha, t), f_{B}(\alpha, t)$, $G_{\gamma \gamma^{\prime}}\left(\alpha_{1}, \alpha_{2}, t\right)$. They, respectively, describe the spatial distribution of particles $A$ and $B$ at an arbitrary time point $t$ in the $\alpha$ nodes of adsorption sites and the correlation between $\gamma, \gamma^{\prime}$ particles [1]. We assume that

$$
\sum_{\alpha} f_{\gamma}(\alpha, t)=N_{\gamma}
$$

where $N_{\gamma}$ is the number of adsorbed particle species $\gamma=A, B$;

$$
G_{A A}\left(\alpha_{1}, \alpha_{2}, t\right) \equiv 0, \quad G_{B B}\left(\alpha_{1}, \alpha_{2}, t\right) \equiv 0, \quad G_{A B}\left(\alpha_{1} \neq \alpha_{2}, t\right)=G_{B A}\left(\alpha_{1} \neq \alpha_{2}, t\right) \equiv 0 .
$$

The criterion for a chemical reaction to occur is formation of a dimer in a separate $\alpha$ adsorption center, namely the condition

$$
g_{A B}\left(\alpha_{1}=\alpha_{2}, t\right)=f_{A B}\left(\alpha_{1}, t\right) \delta_{\alpha_{1}, \alpha_{2}}
$$

is fulfilled $\left(\delta_{\alpha_{1}, \alpha_{2}}\right.$ is the Kronecker symbol [8]). In (4) $g_{A B}\left(\alpha_{1}, \alpha_{2}, t\right)$ is an irreducible part of the correlation function $G_{A B}\left(\alpha_{1}, \alpha_{2}, t\right)$ [1].

Under these assumptions, the system of equations describing reaction-diffusion dynamics for the LH mechanism has the following form [1]:

$$
\begin{aligned}
\frac{\partial f_{A}(\alpha, t)}{\partial t}= & \sum_{\alpha_{1}}\left(K_{A A}\left(\alpha, \alpha_{1}\right)-\hat{D}_{A A}\left(\alpha, \alpha_{1}\right)\right) f_{A}\left(\alpha_{1}, t\right) \\
& +\sum_{\alpha_{1}}\left(K_{A B}\left(\alpha, \alpha_{1}\right)-\hat{D}_{A B}\left(\alpha, \alpha_{1}\right)\right) f_{B}\left(\alpha_{1}, t\right) \\
& +\sum_{\alpha_{1}, \alpha_{2}} P_{A, A B}^{r e a c}\left(\alpha, \alpha_{1}, \alpha_{2}\right)\left(g_{A B}\left(\alpha_{1}, \alpha_{2}, t\right)+f_{A}\left(\alpha_{1}, t\right) f_{B}\left(\alpha_{2}, t\right)\right)+L_{A}\left(f_{A}(\alpha, t)\right), \\
\frac{\partial f_{B}(\alpha, t)}{\partial t}= & \sum_{\alpha_{1}}\left(K_{B B}\left(\alpha, \alpha_{1}\right)-\hat{D}_{B B}\left(\alpha, \alpha_{1}\right)\right) f_{B}\left(\alpha_{1}, t\right) \\
& +\sum_{\alpha_{1}}\left(K_{B A}\left(\alpha, \alpha_{1}\right)-\hat{D}_{B A}\left(\alpha, \alpha_{1}\right)\right) f_{A}\left(\alpha_{1}, t\right) \\
& +\sum_{\alpha_{1}, \alpha_{2}} P_{B, A B}^{r e a c}\left(\alpha, \alpha_{1}, \alpha_{2}\right)\left(g_{B A}\left(\alpha_{1}, \alpha_{2}, t\right)+f_{B}\left(\alpha_{1}, t\right) f_{A}\left(\alpha_{2}, t\right)\right)+L_{B}\left(f_{B}(\alpha, t)\right), \\
\frac{\partial g_{A B}\left(\alpha, \alpha_{1}, t\right)}{\partial t}= & -\sum_{\alpha_{2}}\left(K_{A B}\left(\alpha, \alpha_{2}\right)-\hat{D}_{A B}\left(\alpha, \alpha_{2}\right)\right) f_{A}\left(\alpha_{2}, t\right) f_{B}\left(\alpha_{1}, t\right) \\
& \quad-\sum_{\alpha_{2}}\left(K_{B A}\left(\alpha, \alpha_{2}\right)-\hat{D}_{B A}\left(\alpha, \alpha_{2}\right)\right) f_{A}\left(\alpha_{1}, t\right) f_{B}\left(\alpha_{2}, t\right) \\
& +\sum_{\alpha_{2}, \alpha_{3}} P_{A, A B}^{r e a c}\left(\alpha, \alpha_{1}, \alpha_{2}, \alpha_{3}\right) g_{A B}\left(\alpha_{2}, \alpha_{3}, t\right) .
\end{aligned}
$$

The functions $K_{A A}, K_{B B}, K_{A B}, K_{B A}$ (it is natural to assume that $K_{B A}=K_{A B}$ ) describe the influences of adsorption (interconnections with the catalyst surface) and chemical reaction on the distribution of $A$ or $B$ particle species and indirect correlations between them. The operators $\hat{D}_{\gamma, \gamma^{\prime}}$ describe the effects of diffusion processes on the spatial distributions $f_{\gamma}(\gamma=A, B)$. The functions $P_{A, A B}^{r e a c}, P_{B, A B}^{r e a c}$ describe the influences of chemical reactions on the spatial distributions of $A$ or $B$ particle species and also on the reaction product distribution. The functionals $L_{A}\left(f_{A}\right), L_{B}\left(f_{B}\right)$ describe the presence of external sources for generation of the corresponding particle specie. 
The process of $\mathrm{CO}$ oxidation on platinum-group catalyst surface has in addition certain peculiarities, namely:

- the adsorption of oxygen atoms results from the break up of oxygen molecule $\left(\mathrm{O}_{2}\right)$ near the catalyst's surface into two oxygen atoms $(\mathrm{O})$, either of which adsorbs onto free adsorption site independently;

- the carbon monoxide $(\mathrm{CO})$ molecule adsorbs without breaking up into atoms of carbon $(\mathrm{C})$ and oxygen $(\mathrm{O})$;

- after adsorption the CO molecule can diffuse on the catalyst surface; adsorbed oxygen atoms do not diffuse;

- the product of chemical reaction, the carbon dioxide molecule $\left(\mathrm{CO}_{2}\right)$, desorbs from the surface without breaking up into atoms, does not diffuse on the surface and does not form chemical bonds with $\mathrm{O}$ atoms or $\mathrm{CO}$ molecules adsorbed onto catalyst surface;

- the oxygen atoms do not desorb from the catalyst surface, whereas $\mathrm{CO}$ and $\mathrm{CO}_{2}$ molecules can desorb with different rates. The rate of reaction product $\left(\mathrm{CO}_{2}\right)$ desorption is significantly higher than that of $\mathrm{CO}$.

This allows us to substitute in mathematical model (5)-(7): $\hat{D}_{B B}=\hat{D}_{A B}=\hat{D}_{B A} \equiv 0(A$ is CO, $B$ is O) and $g_{A B}(\alpha, t)=f_{\mathrm{co}_{2}}(\alpha, t)$.

Under these conditions, the mathematical model (in $\alpha$-representation, the lattice representation) of reaction-diffusion equations for the kinetics of $\mathrm{CO}$ oxidation process can be given as follows:

$$
\begin{aligned}
\frac{\partial f_{\mathrm{co}}(\alpha, t)}{\partial t}= & \sum_{\alpha_{1}}\left(K_{\mathrm{co}, \mathrm{co}}\left(\alpha, \alpha_{1}\right)-\hat{D}_{\mathrm{co}, \mathrm{co}}\left(\alpha, \alpha_{1}\right)\right) f_{\mathrm{co}}\left(\alpha_{1}, t\right)+\sum_{\alpha_{1}} K_{\mathrm{co}, \mathrm{o}}\left(\alpha, \alpha_{1}\right) f_{\mathrm{o}}\left(\alpha_{1}, t\right) \\
& +\sum_{\alpha_{1}} K_{\mathrm{co}, \mathrm{o}}^{r e a c}\left(\alpha, \alpha_{1}\right) f_{\mathrm{co}}\left(\alpha_{1}, t\right) f_{\mathrm{o}}\left(\alpha_{2}, t\right)+L_{\mathrm{co}}\left(f_{\mathrm{co}}\right), \\
\frac{\partial f_{\mathrm{o}}(\alpha, t)}{\partial t}= & \sum_{\alpha_{1}} K_{\mathrm{o}, \mathrm{o}}\left(\alpha, \alpha_{1}\right) f_{\mathrm{o}}\left(\alpha_{1}, t\right)+\sum_{\alpha_{1}} K_{\mathrm{co}, \mathrm{o}}\left(\alpha, \alpha_{1}\right) f_{\mathrm{co}}\left(\alpha_{1}, t\right) \\
& +\sum_{\alpha_{1}} K_{\mathrm{co}, \mathrm{o}}^{r e a c}\left(\alpha, \alpha_{1}\right) f_{\mathrm{co}}\left(\alpha_{1}, t\right) f_{\mathrm{o}}\left(\alpha_{1}, t\right)+L_{\mathrm{o}}\left(f_{\mathrm{O}}\right) \\
\frac{\partial f_{\mathrm{co}_{2}}(\alpha, t)}{\partial t}= & -\sum_{\alpha_{1}} K_{\mathrm{co}_{2}}\left(\alpha, \alpha_{1}\right) f_{\mathrm{co}_{2}}\left(\alpha_{1}, t\right)-\sum_{\alpha_{1}} K_{\mathrm{co}, \mathrm{o}}^{\text {reac }}\left(\alpha, \alpha_{1}\right) f_{\mathrm{co}}\left(\alpha_{1}, t\right) f_{\mathrm{o}}\left(\alpha_{1}, t\right) .
\end{aligned}
$$

The system of equations (8)-(10) is a mathematical model (in lattice representation) for describing the kinetics of carbon monoxide oxidation on the platinum-group catalyst surface. Similarly, to the model (5)-(7), the model (8)-(10) is difficult for analysis and study of CO oxidation kinetics due to unknown functions $K_{\mathrm{co}, \mathrm{co}}, K_{\mathrm{o}, \mathrm{o}}, K_{\mathrm{co}, \mathrm{o}}, K_{\mathrm{co}, \mathrm{o}}^{\text {reac }}, K_{\mathrm{CO}_{2}}$ and diffusion operator $\hat{D}_{\mathrm{co}, \mathrm{co}}$.

For a further analysis of the system (8)-(10), a mathematical model of CO oxidation on the catalyst surface, it is convenient to describe this process in terms of coverage functions: $\theta_{\text {co }}(\boldsymbol{R}, t), \theta_{\mathrm{o}}(\boldsymbol{R}, t)$ and $\theta_{\mathrm{CO}_{2}}(\boldsymbol{R}, t)$, where $\boldsymbol{R}=(X, Y)$ is the Cartesian coordinate of an arbitrary point of a catalyst surface. This transition is carried out according to the scheme given in [1], namely, we put:

$$
\frac{1}{N_{\gamma}} \sum_{\alpha}(\cdot) f_{\gamma}(\alpha, t)=\frac{1}{S} \int_{\Omega}(\cdot) \theta_{\gamma}(\boldsymbol{R}, t) d \boldsymbol{R}, \quad \gamma=\left\{\mathrm{CO}, \mathrm{O}, \mathrm{CO}_{2}\right\},
$$

where $\Omega$ is the catalyst surface region, $S$ is the catalyst surface area. Then the system (8)-(10) can be rewritten in terms of coverages as follows:

$$
\begin{aligned}
\frac{\partial \theta_{\mathrm{co}}(\boldsymbol{R}, t)}{\partial t}= & \int_{\Omega} K_{\mathrm{co}, \mathrm{co}}\left(\boldsymbol{R}, \boldsymbol{R}_{1}\right) \theta_{\mathrm{co}}\left(\boldsymbol{R}_{1}, t\right) d \boldsymbol{R}_{1}+\int_{\Omega} K_{\mathrm{co}, \mathrm{o}}\left(\boldsymbol{R}, \boldsymbol{R}_{1}\right) \theta_{\mathrm{o}}\left(\boldsymbol{R}_{1}, t\right) d \boldsymbol{R}_{1} \\
& -\int_{\Omega} \operatorname{div}_{\boldsymbol{R}}\left(\hat{D}_{\mathrm{co}, \mathrm{co}}\left(\boldsymbol{R}, \boldsymbol{R}_{1}\right) \cdot \operatorname{grad}_{\boldsymbol{R}_{1}} \theta_{\mathrm{co}}\left(\boldsymbol{R}_{1}, t\right)\right) d \boldsymbol{R}_{1}
\end{aligned}
$$

Mathematical Modeling and Computing, Vol.5, No. 2, pp. 158-168 (2018) 


$$
\begin{aligned}
& +\int_{\Omega} K_{\mathrm{co}, \mathrm{o}}^{r e a c}\left(\boldsymbol{R}, \boldsymbol{R}_{1}\right) \theta_{\mathrm{co}}\left(\boldsymbol{R}_{1}, t\right) \theta_{\mathrm{o}}\left(\boldsymbol{R}_{1}, t\right) d \boldsymbol{R}_{1}+L_{\mathrm{co}}\left(\theta_{\mathrm{co}}\left(\boldsymbol{R}_{1}, t\right)\right) \\
\frac{\partial \theta_{\mathrm{o}}(\boldsymbol{R}, t)}{\partial t}= & \int_{\Omega} K_{\mathrm{o}, \mathrm{o}}\left(\boldsymbol{R}, \boldsymbol{R}_{1}\right) \theta_{\mathrm{o}}\left(\boldsymbol{R}_{1}, t\right) d \boldsymbol{R}_{1}+\int_{\Omega} K_{\mathrm{o}, \mathrm{co}}\left(\boldsymbol{R}, \boldsymbol{R}_{1}\right) \theta_{\mathrm{co}}\left(\boldsymbol{R}_{1}, t\right) d \boldsymbol{R}_{1} \\
& +\int_{\Omega} K_{\mathrm{o}, \mathrm{co}}^{r e a c}\left(\boldsymbol{R}, \boldsymbol{R}_{1}\right) \theta_{\mathrm{co}}\left(\boldsymbol{R}_{1}, t\right) \theta_{\mathrm{o}}\left(\boldsymbol{R}_{1}, t\right) d \boldsymbol{R}_{1}+L_{\mathrm{o}}\left(\theta_{\mathrm{o}}\left(\boldsymbol{R}_{1}, t\right)\right) \\
\frac{\partial \theta_{\mathrm{co}_{2}}(\boldsymbol{R}, t)}{\partial t}= & \int_{\Omega} K_{\mathrm{co}_{2}, \mathrm{co} 2}\left(\boldsymbol{R}, \boldsymbol{R}_{1}\right) \theta_{\mathrm{co} 2}\left(\boldsymbol{R}_{1}, t\right) d \boldsymbol{R}_{1}-\int_{\Omega} K_{\mathrm{o}, \mathrm{co}}^{r e a c}\left(\boldsymbol{R}, \boldsymbol{R}_{1}\right) \theta_{\mathrm{o}}\left(\boldsymbol{R}_{1}, t\right) \theta_{\mathrm{co}}\left(\boldsymbol{R}_{1}, t\right) d \boldsymbol{R}_{1} .
\end{aligned}
$$

The system of equations (12)-(14) is a continuum mathematical model for describing reactiondiffusion processes of carbon monoxide $(\mathrm{CO})$ oxidation on a flat surface of metal catalyst $(\mathrm{Pt})$ written in term of coverages. The effects of the catalyst structure, oxidation processes and diffusion are incorporated in functions $K_{\mathrm{co}, \mathrm{co}}, K_{\mathrm{o}, \mathrm{co}}, K_{\mathrm{O}_{,} \mathrm{CO}_{2}}, K_{\mathrm{Co}, \mathrm{CO}_{2}}, K_{\mathrm{CO}_{2}, \mathrm{CO}_{2}}$ and diffusion coefficient $\hat{D}_{\mathrm{co}, \mathrm{co}}$.

Solutions of this system for the given initial and boundary conditions on the coverages $\theta_{\mathrm{co}}, \theta_{\mathrm{o}}, \theta_{\mathrm{Co}_{2}}$ specify the dynamics of $\mathrm{CO}$ oxidation chemical reaction when diffusion processes are present.

Since the system of equations (12)-(14) is a nonlocal nonlinear system, we perform the following simplifications which take into account the specifics of course of carbon monoxide oxidation reaction.

We substitute in (12)-(14) that:

$$
\begin{aligned}
K_{\mathrm{co}, \mathrm{co}}\left(\boldsymbol{R}, \boldsymbol{R}_{1}\right) & =\left(k_{\mathrm{co}}^{\text {adsorption }}-k_{\mathrm{co}}^{\text {desorption }}\right) \cdot \delta\left(\boldsymbol{R}-\boldsymbol{R}_{1}\right), \\
K_{\mathrm{o}, \mathrm{o}}\left(\boldsymbol{R}, \boldsymbol{R}_{1}\right) & =\left(k_{\mathrm{o}}^{\text {adsorption }}-k_{\mathrm{o}}^{\text {desorption }}\right) \cdot \delta\left(\boldsymbol{R}-\boldsymbol{R}_{1}\right), \\
K_{\mathrm{o}, \mathrm{co}}\left(\boldsymbol{R}, \boldsymbol{R}_{1}\right) & =k_{\mathrm{o}, \mathrm{co}} \cdot \delta\left(\boldsymbol{R}-\boldsymbol{R}_{1}\right), \\
K_{\mathrm{o}, \mathrm{co}}^{r e a c}\left(\boldsymbol{R}, \boldsymbol{R}_{1}\right) & =K_{\mathrm{co}, \mathrm{o}}^{\text {reac }}\left(\boldsymbol{R}, \boldsymbol{R}_{1}\right)=k^{\text {reaction }} \cdot \delta\left(\boldsymbol{R}-\boldsymbol{R}_{1}\right), \\
K_{\mathrm{co}_{2}, \mathrm{co} 2}\left(\boldsymbol{R}, \boldsymbol{R}_{1}\right) & =k_{\mathrm{co} 2}^{\text {desorption }} \cdot \delta\left(\boldsymbol{R}-\boldsymbol{R}_{1}\right), \\
\hat{D}_{\mathrm{co}, \mathrm{co}}\left(\boldsymbol{R}, \boldsymbol{R}_{1}\right) & =D_{\mathrm{co}}(\boldsymbol{R}) \cdot \delta\left(\boldsymbol{R}-\boldsymbol{R}_{1}\right),
\end{aligned}
$$

$D_{\text {co }}(\boldsymbol{R})$ is a local diffusion coefficient of CO molecule.

In expressions (15)-(20):

$$
\delta(\boldsymbol{R})=\delta(X) \delta(Y)
$$

where $\delta(\cdot)$ is the Dirac delta function [8].

These simplifications allow us to study model (12)-(14) of CO oxidation when the influence of catalyst surface and the presence of adsorbed $\mathrm{CO}$ and $\mathrm{O}$ molecules are most possibly accounted. Indeed, if coefficients $k_{\mathrm{co}}^{\text {adsorption }}, k_{\mathrm{O}}^{\text {adsorption }}, k_{\mathrm{co}}^{\text {desorption }}, k_{\mathrm{O}}^{\text {desorption }}, k_{\mathrm{CO}_{2}}^{\text {desorption }}$ are taken from the experimental data for the kinetics of $\mathrm{CO}$ oxidation on the Pt catalyst surface, the influences of catalyst and correlation effects during adsorption and diffusion can be considered to be accounted for.

We consider now models for description of sources $L_{\mathrm{co}}\left(\theta_{\mathrm{co}}\right)$ and $L_{\mathrm{o}}\left(\theta_{\mathrm{o}}\right)$. These sources can be modeled as follows:

$$
L_{\mathrm{co}}\left(\theta_{\mathrm{co}}\right)=\kappa_{\mathrm{co}} p_{\mathrm{co}} s_{\mathrm{co}}^{0}\left(1-\theta_{\mathrm{co}}^{3}\right), \quad L_{\mathrm{o}}\left(\theta_{\mathrm{o}}\right)=\kappa_{\mathrm{o}} p_{\mathrm{o}} s_{\mathrm{o}}^{0}\left(\theta^{*}\right)^{2} .
$$

In $(21) s_{\mathrm{co}}^{0}, s_{\mathrm{o}}^{0}$ are carbon monoxide and oxygen sticking coefficients (initial probabilities) $[9,10] ; p_{\mathrm{co}}$ and $p_{\mathrm{o}}$ are the partial pressures of the corresponding species, which are specified by experimental conditions; $\theta^{*}$ is the coverage of catalyst surface free sites. The stoichiometric equilibrium conditions [11] require fulfillment of equality:

$$
\theta_{\mathrm{co}}+\theta_{\mathrm{O}}+\theta_{\mathrm{co}_{2}}+\theta^{*} \equiv 1
$$


Therefore we will henceforth determine the number of free active sites $\theta^{*}$ from condition (22):

$$
\theta^{*}=1-\theta_{\mathrm{co}}-\theta_{\mathrm{o}}-\theta_{\mathrm{Co}_{2}} .
$$

If we substitute into system (12)-(14) expressions (15)-(20) instead of functions $K_{\text {co,co }}, K_{\text {o,co }}$, $K_{\mathrm{o}_{2} \mathrm{Co}_{2}}, K_{\mathrm{Co}, \mathrm{Co}_{2}}, K_{\mathrm{Co}_{2}, \mathrm{co}_{2}}, \hat{D}_{\mathrm{co}, \mathrm{co}}$ and use the known identity [8]:

$$
\int_{\Omega} \delta^{\prime}(\boldsymbol{R}) f(\boldsymbol{R}) d \boldsymbol{R}=-\int_{\Omega} \delta(\boldsymbol{R}) \operatorname{grad}_{\boldsymbol{R}} f(\boldsymbol{R}) d \boldsymbol{R}
$$

we obtain a simplified mathematical model for CO oxidation, namely:

$$
\begin{aligned}
& \frac{\partial \theta_{\mathrm{co}}(\boldsymbol{R}, t)}{\partial t}= p_{\mathrm{co}} s_{\mathrm{co}}^{0} \kappa_{\mathrm{co}}\left(1-\theta_{\mathrm{co}}^{3}(\boldsymbol{R}, t)\right)-k^{\text {reaction }} \theta_{\mathrm{co}}(\boldsymbol{R}, t) \theta_{\mathrm{o}}(\boldsymbol{R}, t)-k_{\mathrm{co}}^{\text {desorption }} \theta_{\mathrm{co}}(\boldsymbol{R}, t) \\
&+\operatorname{div}_{\boldsymbol{R}}\left(D_{\mathrm{co}}(\boldsymbol{R}) \operatorname{grad}_{\boldsymbol{R}} \theta_{\mathrm{co}}(\boldsymbol{R}, t)\right), \\
& \frac{\partial \theta_{\mathrm{o}}(\boldsymbol{R}, t)}{\partial t}= p_{\mathrm{o}} s_{\mathrm{o}}^{0} \kappa_{\mathrm{o}}\left(1-\theta_{\mathrm{co}}(\boldsymbol{R}, t)-\theta_{\mathrm{o}}(\boldsymbol{R}, t)-\theta_{\mathrm{co}_{2}}(\boldsymbol{R}, t)\right)^{2}-k^{\text {reaction }} \theta_{\mathrm{co}}(\boldsymbol{R}, t) \theta_{\mathrm{o}}(\boldsymbol{R}, t), \\
& \frac{\partial \theta_{\mathrm{co}_{2}(\boldsymbol{R}, t)}^{\partial t}=}{k^{\text {reaction }} \theta_{\mathrm{co}}(\boldsymbol{R}, t) \theta_{\mathrm{o}}(\boldsymbol{R}, t)-k_{\mathrm{co} 2}^{\text {desorption }} \theta_{\mathrm{co}_{2}}(\boldsymbol{R}, t) .}
\end{aligned}
$$

The system (24)-(26) is a generalization of the one-dimensional Ziff-Gulari-Barshad (ZGB) model [12] for $\mathrm{CO}$ oxidation on the metal catalyst surface. It takes into account both the two-dimensionality of the catalyst surface and the finiteness of oxidation product $\mathrm{CO}_{2}$ desorption.

\section{Investigation of the process of carbon monoxide oxidation on platinum [111] catalyst surface}

We consider the model (24)-(26) of catalytic CO oxidation reaction on $\mathrm{Pt}(111)$ surface, which is stable in $(1 \times 1)$ structure and does not reconstruct into new configurations under the influence of adsorbed CO [3]. The catalyst surface is assumed to be flat with a given Cartesian coordinate system XOY. We introduce new variables in the equations $(24)-(26)$ :

$$
u=\theta_{\mathrm{co}}, \quad v=\theta_{\mathrm{O}}
$$

and take into account that desorption of reaction product $\left(\mathrm{CO}_{2}\right)$ can be considered instantaneous when modeling CO oxidation on the Pt-catalyst surface [13]. Then the equations (24)-(26) are rewritten in the new variables:

$$
\begin{aligned}
& \frac{\partial u}{\partial t}=p_{u} \kappa_{u} s_{u}^{0}\left(1-\left(\frac{u}{u_{s a t}}\right)^{3}\right)-k_{1} u v-k_{2} u+D_{x} \frac{\partial^{2} u}{\partial x^{2}}+D_{y} \frac{\partial^{2} u}{\partial y^{2}} \\
& \frac{\partial v}{\partial t}=p_{v} \kappa_{v} s_{v}^{0}\left(1-\frac{u}{u_{s a t}}-\frac{v}{v_{s a t}}\right)^{2}-k_{1} u v .
\end{aligned}
$$

Here $p_{u}, p_{v}$ are the partial pressures of $\mathrm{CO}$ and $\mathrm{O}_{2}$, respectively; $\kappa_{u}, \kappa_{v}$ are the impingement rates; $s_{u}^{0}, s_{v}^{0}$ are the sticking coefficients (initial probabilities); $u_{s a t}, v_{s a t}$ refer to the maximum coverages, namely the saturation coverages; $D_{x}, D_{y}$ are CO diffusion coefficients in $O X$ and $O Y$-axis directions, respectively. Coefficients $k_{1}, k_{2}$, which characterize the rates of reaction and desorption of $\mathrm{CO}$ molecule from the catalyst surface, are temperature $T$ dependent and are determined by the Arrhenius equations [14]:

$$
k_{i}=k_{i}(T)=k_{i}^{0} \exp \left(-\frac{E_{i}}{R T}\right), \quad i=1,2 .
$$


Here $k_{i}^{0}$ are the temperature independent coefficients; $E_{i}$ are the activation energies of reaction (when $i=1$ ) and CO desorption (when $i=2$ ); $R$ is the universal gas constant [15].

The equations (27)-(28) are transformed into dimensionless form by substituting:

$$
u=u_{\text {sat }} U, \quad v=v_{\text {sat }} V, \quad x=l_{0} \tilde{x}, \quad y=l_{0} \tilde{y}, \quad t=t_{c} \tilde{t},
$$

where

$$
t_{c}=\frac{v_{s a t}}{p_{u} \kappa_{u} s_{u}^{0}} .
$$

The parameter $l_{0}$ is chosen according to experimental data for the size of Pt-crystal [16], $l_{0} \sim 10^{-3} \mathrm{~cm}$.

In dimensionless form the equations (27)-(28) compose the proposed mathematical model for reaction of $\mathrm{CO}$ oxidation on Pt surface:

$$
\left\{\begin{aligned}
\frac{\partial U}{\partial \tilde{t}} & =\frac{v_{s a t}}{u_{s a t}}\left(1-U^{3}\right)-\tilde{k}_{1} v_{s a t} U V-\tilde{k}_{2} U+\tilde{D}_{x}\left(\frac{\partial^{2} U}{\partial \tilde{x}^{2}}+D_{0} \frac{\partial^{2} U}{\partial \tilde{y}^{2}}\right) \\
& \equiv P(U, V)+\tilde{D}_{x}\left(\frac{\partial^{2} U}{\partial \tilde{x}^{2}}+D_{0} \frac{\partial^{2} U}{\partial \tilde{y}^{2}}\right), \\
\frac{\partial V}{\partial \tilde{t}} & =\tilde{p}_{v} s_{v}^{0}(1-U-V)^{2}-\tilde{k}_{1} u_{s a t} U V \equiv Q(U, V) .
\end{aligned}\right.
$$

Here:

$$
\tilde{p}_{v}=\frac{p_{v} \kappa_{v} t_{c}}{v_{\text {sat }}}, \quad \tilde{D}_{x}=\frac{D_{x} t_{c}}{l_{0}^{2}}, \quad D_{0}=\frac{D_{y}}{D_{x}}, \quad \tilde{k}_{i}=k_{i} t_{c}, \quad i=1,2 .
$$

The system (30) is a system of two nonlinear partial differential equations, so its solution will be searched numerically. Parameter values used in numerical calculations are given in Tabl. 1 [17-22].

Table 1. Parameters of mathematical model for CO oxidation on $\mathrm{Pt}(111)$ surface.

\begin{tabular}{|l|l|l|l|}
\hline $\mathrm{CO}$ & Partial pressure & $p_{u}$ & $\sim 10^{-5}$ Torr \\
& Impingement rate & $\kappa_{u}$ & $4.2 \cdot 10^{5} \mathrm{~s}^{-1} \cdot \operatorname{Torr}^{-1}$ \\
& Sticking coefficient & $s_{u}^{0}$ & 0.84 \\
& Saturation coverage & $u_{\text {sat }}$ & 0.5 \\
& Diffusion coefficient & $D_{x}$ & $1.2 \cdot 10^{-7} \mathrm{~cm}^{2} \cdot \mathrm{s}^{-1}$ \\
& Partial pressure & $p_{v}$ & $\sim 10^{-5} \mathrm{Torr}$ \\
& Impingement rate & $\kappa_{v}$ & $7.8 \cdot 10^{5} \mathrm{~s}^{-1} \cdot \mathrm{Torr}^{-1}$ \\
& Sticking coefficient & $s_{v}^{0}$ & 0.025 \\
& Saturation coverage & $v_{\text {sat }}$ & 0.25 \\
Rates & $k_{1}^{0}$ & $4.7 \cdot 10^{6} \mathrm{~s}^{-1}$ \\
& Reaction & $E_{1}$ & $13 \mathrm{kcal} \cdot \mathrm{mol}^{-1}$ \\
& & $k_{2}^{0}$ & $1.25 \cdot 10^{15} \mathrm{~s}^{-1}$ \\
& Desorption of CO & $E_{2}$ & $34.9 \mathrm{kcal} \cdot \mathrm{mol}^{-1}$ \\
\hline
\end{tabular}

Before conducting a complete analysis of the model (30) first we consider the issue of existence and stability of steady-state solutions $\left(U^{s}, V^{s}\right)$ for a system where diffusion processes are absent, namely:

$$
\frac{\partial U}{\partial \tilde{t}}=P(U, V), \quad \frac{\partial V}{\partial \tilde{t}}=Q(U, V) .
$$

These solutions satisfy the system of algebraic equations:

$$
P\left(U^{s}, V^{s}\right)=0, \quad Q\left(U^{s}, V^{s}\right)=0 .
$$


The results of numerical analysis show that there exists a real steady-state solution $\left(U^{s}, V^{s}\right)$ of system (32) for arbitrary values of partial pressures $p_{u}, p_{v} \sim 10^{-5}$ Torr and: $0 \leqslant U^{s} \leqslant 1,0 \leqslant V^{s} \leqslant 1$. The graphic representation of $\left(U^{s}, V^{s}\right)$ as a function of partial pressure $p_{u}$ is given in Fig. 1 for certain values of $p_{v}=20.1 \cdot 10^{-5}$ Torr and $T=540 \mathrm{~K}$. It can be seen that at pressure $p_{u}=5.94 \cdot 10^{-6}$ Torr a transition occurs from a state with high reactivity when adsorbed CO molecules and oxygen atoms are located on the surface and enter into chemical reaction of oxidation, to a state with low reactivity when almost entire surface of the catalyst is covered with adsorbed $\mathrm{CO}$, which disables oxidation reaction.

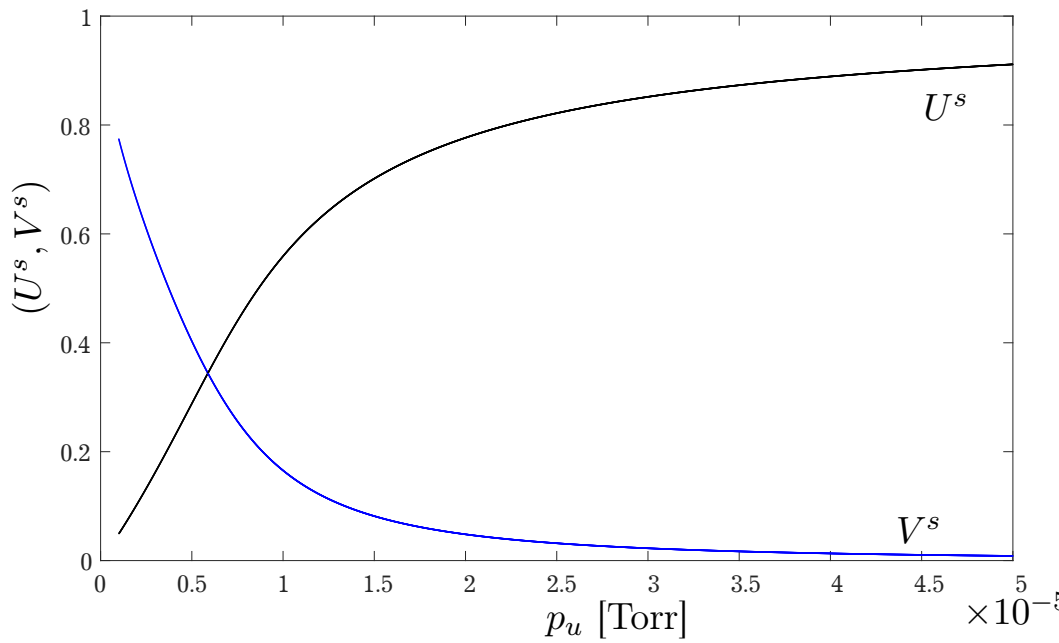

Fig. 1. Steady-state solution of system (32) as a function of partial pressure $p_{u}$ for $p_{v}=20.1 \cdot 10^{-5}$ Torr.

To analyze the stability of solutions $\left(U^{s}, V^{s}\right)$ of system (32), timedependent small deviations from the steady states $\delta U(\tilde{t}), \delta V(\tilde{t})$ are introduced:

$$
U=U^{s}+\delta U(\tilde{t}), \quad V=V^{s}+\delta V(\tilde{t}) .
$$

Then the linearized system (32) near $\left(U^{s}, V^{s}\right)$ looks as follows:

$$
\frac{d}{d \tilde{t}}\|\delta U \quad \delta V\|^{\top}=\boldsymbol{M} \cdot\|\delta U \quad \delta V\|^{\top}
$$

$$
\boldsymbol{M}=\left\|\begin{array}{cc}
P_{U}^{\prime} & P_{V}^{\prime} \\
Q_{U}^{\prime} & Q_{V}^{\prime}
\end{array}\right\|_{\left(U^{s}, V^{s}\right)}
$$

is the Jacobian matrix [8] for the system of functions (32), where all partial derivatives are calculated at a stationary point $\left(U^{s}, V^{s}\right)$.

We look for the solutions $(\delta U, \delta V)$ of the system (34) in a form:

$$
\delta U=C_{1} e^{\lambda_{1} \tilde{t}}, \quad \delta V=C_{2} e^{\lambda_{2} \tilde{t}}
$$

where $\lambda_{i}$ are the eigenvalues of Jacobian matrix (35), $C_{i}$ are the constants $(i=1,2)$.

The calculation of eigenvalues $\lambda$ reduces to solving equation:

$$
\operatorname{det}\left\|\begin{array}{cc}
P_{U}^{\prime}-\lambda & P_{V}^{\prime} \\
Q_{U}^{\prime} & Q_{V}^{\prime}-\lambda
\end{array}\right\|_{\left(U^{s}, V^{s}\right)}=0
$$

or the following square equation:

$$
\lambda^{2}-\lambda \operatorname{tr} \boldsymbol{M}+\operatorname{det} \boldsymbol{M}=0
$$

where

$$
\operatorname{tr} \boldsymbol{M}=P_{U}^{\prime}+Q_{V}^{\prime}, \quad \operatorname{det} \boldsymbol{M}=P_{U}^{\prime} Q_{V}^{\prime}-P_{V}^{\prime} Q_{U}^{\prime}
$$

are the trace and determinant of matrix $\boldsymbol{M}$, respectively.

The steady-state solutions $\left(U^{s}, V^{s}\right)$ are stable when $\operatorname{Re}\left(\lambda_{1,2}\right)<0$. Since the discriminant of equation (38) is non-negative for the given model parameters:

$$
D=\operatorname{tr}^{2} \boldsymbol{M}-4 \operatorname{det} \boldsymbol{M}=\left(P_{U}^{\prime}-Q_{V}^{\prime}\right)^{2}+4 P_{V}^{\prime} Q_{U}^{\prime} \geqslant 0,
$$

the roots

$$
\lambda_{1,2}=\frac{1}{2}\left(\operatorname{tr} \boldsymbol{M} \pm \sqrt{\operatorname{tr}^{2} \boldsymbol{M}-4 \operatorname{det} \boldsymbol{M}}\right) .
$$


are real and have negative values if

$$
\operatorname{det} \boldsymbol{M}>0 .
$$

The condition (41) is the condition for stability of steady-state solutions $\left(U^{s}, V^{s}\right)$ of the system (32). After numerical analysis of the condition (41) for the given model parameters, we find that the system (32) is stable for arbitrary partial pressures $p_{u}, p_{v} \sim 10^{-5}$ Torr.

Thus, the region of auto-oscillatory mode arising from Hopf instability [23] does not exist for model (30). Therefore, only bistable behavior of catalytic reaction will be observed. That is the system moves from one stable state with high catalytic activity to another one with low catalytic activity.

To investigate the influence of spatial effects on the model stability, we consider system (30) which takes into account diffusion processes. The small deviations from the steady states $\left(U^{s}, V^{s}\right)$ are introduced:

$$
U=U^{s}+\delta U(\tilde{x}, \tilde{y}, \tilde{t}), \quad V=V^{s}+\delta V(\tilde{x}, \tilde{y}, \tilde{t})
$$

where $\delta U(\tilde{x}, \tilde{y}, \tilde{t}), \delta V(\tilde{x}, \tilde{y}, \tilde{t})$ are small perturbations dependent on $\tilde{x}, \tilde{y}$ coordinates and time $\tilde{t}$. The linearized system $(30)$ near $\left(U^{s}, V^{s}\right)$ is written as:

$$
\frac{\partial}{\partial \tilde{t}}\|\delta U \quad \delta V\|^{\top}=\boldsymbol{M} \cdot\|\delta U \quad \delta V\|^{\top}+\tilde{D}_{x}\left(\frac{\partial^{2}}{\partial \tilde{x}^{2}}+D_{0} \frac{\partial^{2}}{\partial \tilde{y}^{2}}\right)\|\delta U \quad 0\|^{\top},
$$

where $\boldsymbol{M}$ is the Jacobian matrix defined by (35).

We look for the solutions $(\delta U, \delta V)$ of the system $(42)$ in a form:

$$
\delta U=C_{1} e^{\lambda_{1} \tilde{t}+i \boldsymbol{k} R}, \quad \delta V=C_{2} e^{\lambda_{2} \tilde{t}+i \boldsymbol{k} \boldsymbol{R}},
$$

where $\lambda_{i}, i=1,2$ are the eigenvalues for temporal growth, $\boldsymbol{k}=\left(k_{x} ; k_{y}\right)$ are the wavenumbers (the eigenvalues of the spatial problem (42)).

Then the problem of stability analysis reduces to finding the eigenvalues $\lambda, k_{x}, k_{y}$ from equation:

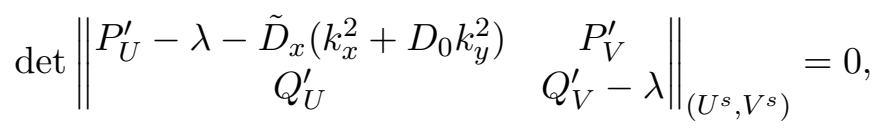

or

$$
\lambda^{2}+\lambda\left(\tilde{D}_{x}\left(k_{x}^{2}+D_{0} k_{y}^{2}\right)-\operatorname{tr} \boldsymbol{M}\right)-\tilde{D}_{x}\left(k_{x}^{2}+D_{0} k_{y}^{2}\right) Q_{V}^{\prime}+\operatorname{det} \boldsymbol{M}=0,
$$

where all partial derivatives are calculated at a stationary point $\left(U^{s}, V^{s}\right)$.

The solutions of the equation (45) are written as

$$
\lambda_{1,2}=\frac{1}{2}\left(\operatorname{tr} \boldsymbol{M}-\tilde{D}_{x}\left(k_{x}^{2}+D_{0} k_{y}^{2}\right) \pm \sqrt{D_{1}}\right),
$$

where $D_{1}$ is the discriminant of the equation (45):

$$
D_{1}=D+\tilde{D}_{x}\left(k_{x}^{2}+D_{0} k_{y}^{2}\right)\left\{\tilde{D}_{x}\left(k_{x}^{2}+D_{0} k_{y}^{2}\right)+2\left(Q_{V}^{\prime}-P_{U}^{\prime}\right)\right\} .
$$

Here $D$ is the discriminant (39).

Obviously, for the given model parameters: $\operatorname{Re}\left(\lambda_{1,2}\right)<0$ with arbitrary $k_{x}, k_{y} \neq 0$. This means that steady-state solutions $\left(U^{s}, V^{s}\right)$ of the system (30) are stable for the arbitrary $k_{x}, k_{y} \neq 0$. Therefore, the conditions for Turing bifurcation [24] to occur are not satisfied; i.e., the system (30) remains stable when diffusion effects are present.

The results of numerical analysis of the two-dimensional mathematical model (30) for CO oxidation on $\mathrm{Pt}(111)$ surface are presented in Figs. 2-3. These figures show that at pressures $p_{u}=4.5 \cdot 10^{-6}$ Torr, 


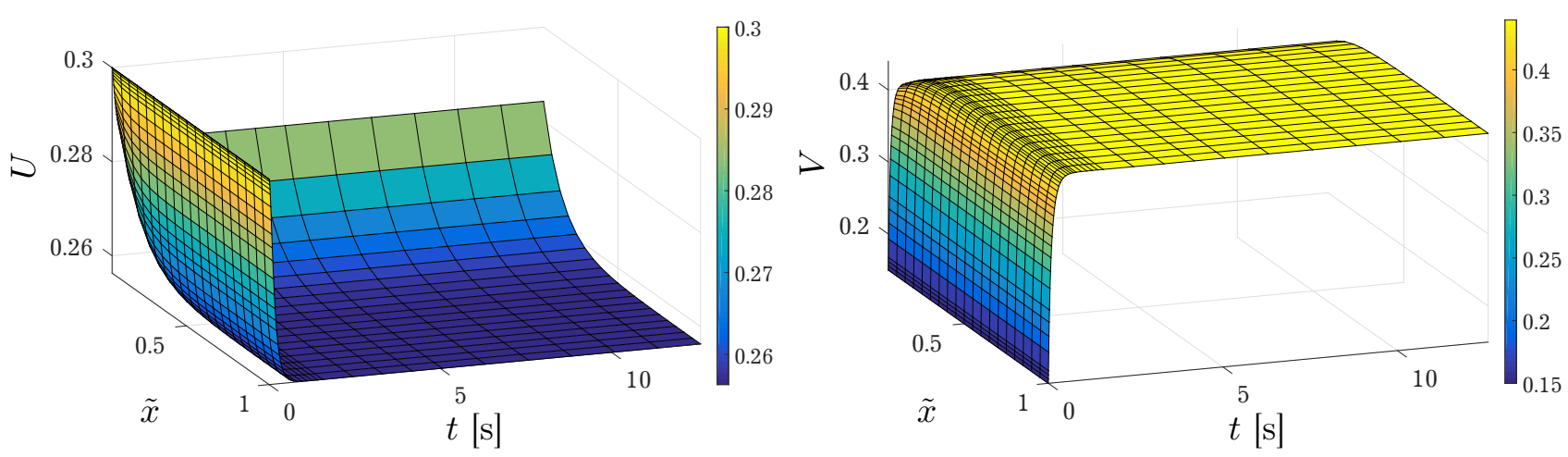

Fig. 2. Dependency of $\mathrm{CO} U(\tilde{x}, \tilde{y}, \tilde{t})$ and $\mathrm{O} V(\tilde{x}, \tilde{y}, \tilde{t})$ surface coverages for $\frac{D_{x}}{D_{y}}=10, l_{0}=10^{-3} \mathrm{~cm}, T=540 \mathrm{~K}$, $p_{u}=4.5 \cdot 10^{-6}$ Torr, $p_{v}=20.1 \cdot 10^{-5}$ Torr, $\tilde{y}=0.4$.

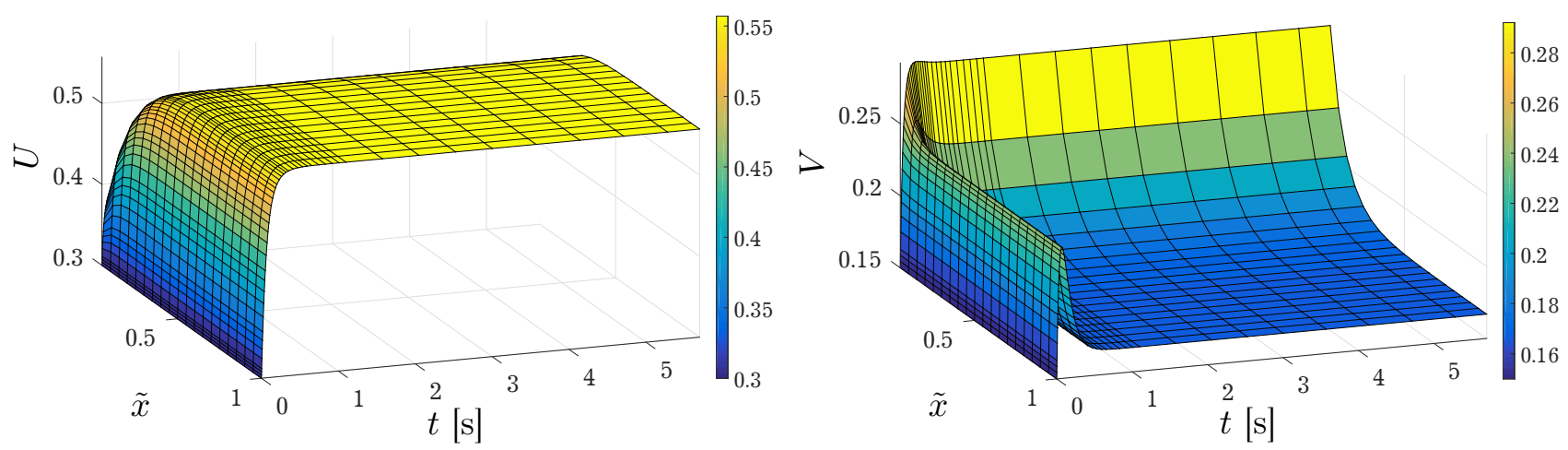

Fig. 3. Dependency of $\mathrm{CO} U(\tilde{x}, \tilde{y}, \tilde{t})$ and $\mathrm{O} V(\tilde{x}, \tilde{y}, \tilde{t})$ surface coverages for $\frac{D_{x}}{D_{y}}=10, l_{0}=10^{-3} \mathrm{~cm}, T=540 \mathrm{~K}$, $p_{u}=9.95 \cdot 10^{-6}$ Torr, $p_{v}=20.1 \cdot 10^{-5}$ Torr, $\tilde{y}=0.4$.

$p_{v}=20.1 \cdot 10^{-5}$ Torr there are adsorbed CO molecules and $\mathrm{O}$ atoms on the catalyst surface, therefore, we observe a state with high reactivity and $\mathrm{CO}_{2}$ formation. On the contrary, at $p_{u}=9.95 \cdot 10^{-6}$ Torr, $p_{v}=20.1 \cdot 10^{-5}$ Torr adsorbed CO blocks oxygen adsorption, so the surface coverage of $\mathrm{O}$ falls and the system moves to a state with low reactivity. The auto-oscillatory mode for model (30) is not observed.

Such a bistable behavior of CO oxidation reaction on $\operatorname{Pt}(111)$ surface, when the system moves from a stable state with high catalytic activity to another stable state with low catalytic activity, is consistent with experimental findings [3,25].

Transition to the stationary mode is accompanied by decrease in reaction yield. So, in practice, when constructing the catalyst surface a crystallite with (110) working facet should be used.

\section{Conclusions}

A mathematical model of reaction-diffusion processes is substantiated and built for the LangmuirHinshelwood mechanism ( $\mathrm{LH})$ on the surface of metal catalyst. It takes into account the peculiarities of occurrence of oxidation reactions on platinum surface. Mathematical modeling of CO oxidation process was carried out for $\mathrm{Pt}(111)$ surface, of which, unlike (110) facet, the structural phase transition is not characteristic. Stability regions of reaction and conditions for Hopf and Turing instabilities to arise were investigated. It was established that the system is stable at partial pressures $p_{u}$ and $p_{v} \sim 10^{-5}$ Torr. Therefore, the region of auto-oscillatory mode does not exist for the given model parameters. The qualitative agreement of results for numerical modeling with experimental data for CO oxidation reaction on $\mathrm{Pt}(111)$ was obtained. 
[1] Kostrobij P. P., Tokarchuk M. V., Markovych B. M., Ignatjuk V. V., Gnativ B. V. Reakcijno-difuzijni procesi v sistemah "metal-gaz". Lviv Polytechnic National University, Lviv (2009), (in Ukrainian).

[2] Kato H. S., Okuyama H., Yoshinobu J., Kawai M. Estimation of direct and indirect interactions between CO molecules on Pd(110). Surf. Sci. 513 (2), 239-248 (2002).

[3] Imbihl R., Ertl G. Oscillatory Kinetics in Heterogeneous Catalysis. Chemical Reviews. 95 (3), 697-733 (1995).

[4] March N. H. Chemical Bonds Outside Metal Surfaces. Plenum Press, New York (1986).

[5] Yucel S. Theory of ortho-para conversion in hydrogen adsorbed on metal and paramagnetic surfaces at low temperatures. Phys. Rev. B. 39 (5), 3104-3115 (1989).

[6] KostrobijP., Markovych B., Vasylenko A., Tokarchuk M., RudavskijY. Nonequilibrium statistical Zubarev's operator and Green's functions for an inhomogeneous electron gas. Condens. Matter Phys. 9 (3), 519-533 (2006).

[7] Langmuir I. The mechanism of the catalytic action of platinum in the reactions $2 \mathrm{CO}+\mathrm{O}_{2}=2 \mathrm{CO}_{2}$ and $2 \mathrm{H}_{2}+\mathrm{O}_{2}=2 \mathrm{H}_{2} \mathrm{O}$. Trans. Faraday Soc. 17, 621-654 (1922).

[8] Korn G. A., Korn T. M. Mathematical Handbook for Scientists and Engineers: Definitions, Theorems, and Formulas for Reference and Review. Dover Publications (2000).

[9] Wilf M., Dawson P. The adsorption and desorption of oxygen on the Pt(110) surface; A thermal desorption and LEED/AES study. Surf. Science. 65 (2), 399-418 (1977).

[10] Gasser R. P. H., Smith E. B. A surface mobility parameter for chemisorption. Chem. Phys. Lett. 1, 457-458 (1967).

[11] Kafarov V. V. Metody kibernetiki v himii i himicheskoj tehnologii. Himija, Moskva (1976), (in Russian).

[12] Ziff R. M., Gulari E., Barshad Y. Kinetic phase transitions in an irreversible surface-reaction model. Phys. Rev. Lett. 56 (24), 2553-2556 (1986).

[13] Kostrobij P., Ryzha I. Two-dimensional mathematical model for carbon monoxide oxidation process on the platinum catalyst surface. Chem. Chem. Technol. 12 (4), 451-455 (2018).

[14] Connors K. A. Chemical Kinetics: The Study of Reaction Rates in Solution. VCH Publishers, New York (1990).

[15] Kuchling H. Taschenbuch der Physik. Carl Hanser (Verlag) (2014).

[16] Spiel C., VogelD., Suchorski Y., Drachsel W., SchlöglR., Rupprechter G. Catalytic CO oxidation on individual (110) domains of a polycrystalline Pt foil: Local reaction kinetics by PEEM. Catalysis Letters. 141 (5), 625-632 (2011).

[17] Campbell C., Ertl G., Kuipers H., Segner J. A molecular beam investigation of the interactions of CO with a Pt(111) surface. Surf. Science. 107 (1), 207-219 (1981).

[18] Ertl G., Neumann M., Streit K. M. Chemisorption of CO on the Pt(111) surface. Surf. Science. 64 (2), 393-410 (1977).

[19] Campbell C., Ertl G., Kuipers H., Segner J. A molecular beam study of the adsorption and desorption of oxygen from a Pt(111) surface. Surf. Science. 107 (1), 220-236 (1981).

[20] Gland J. L. Molecular and atomic adsorption of oxygen on the $\mathrm{Pt}(111)$ and $\mathrm{Pt}(\mathrm{S})-12(111) \times(111)$ surfaces. Surf. Science. 93 (2-3), 487-514 (1980).

[21] Kinne M., Fuhrmann T., Zhu J. F., Whelan C. M., Denecke R., Steinrück H. P. Kinetics of the CO oxidation reaction on $\mathrm{Pt}(111)$ studied by in situ high-resolution x-ray photoelectron spectroscopy. J. Chem. Phys. 120 (15), 7113-7122 (2004).

[22] Krischer K., Eiswirth M., ErtlG. Oscillatory CO oxidation on $\mathrm{Pt}(110)$ : Modeling of temporal selforganization. J. Chem. Phys. 96 (12), 9161-9172 (1992).

[23] Kuznetsov Y. Elements of applied bifurcation theory. New York, Springer (1995).

[24] Hoyle R. Pattern Formation. New York, Cambridge University Press (2006).

[25] Ehsasi M., Matloch M., Frank O., Block J. H. Steady and nonsteady rates of reaction in a heterogeneously catalyzed reaction: Oxidation of $\mathrm{CO}$ on platinum, experiments and simulations. J. Chem. Phys. 91 (8), 4949-4960 (1989). 


\title{
Математична модель оксидації чадного газу: вплив структури поверхні каталізатора
}

\author{
Костробій П., Рижа І., Маркович Б. \\ Національний університет “Львівсъка політехніка", \\ вул. С. Бандери, 12, Лввів, 79013, Україна
}

\begin{abstract}
Запропоновано обгрунтовану математичну модель опису реакційно-дифузійних процесів двосортної суміші, адсорбованих на поверхні каталізатора частинок. Показано, що для реакції окиснення чадного газу (CO) запропонована модель узагальнює одновимірну модель ZGB. Досліджено кінетику окиснення СО на стійких щодо перебудови гранях кристала платини (Pt).
\end{abstract}

Ключові слова: каталітична реакція окиснення, реакиійно-дифузійна модель, математичне моделювання реакційно-дифузійних процесів.

2000 MSC: 37E99, 82D99, 82C21

УдК: 538.9 